\title{
On the Design of Invoicing Practices in International Trade
}

\author{
JEAN-MARIE VIAENE \\ Erasmus Universiteit Rotterdam, The Netherlands
}

CASPER G. DE VRIES

Katholieke Universiteit Leuven, Belgium

Key words: invoicing, sequential bargaining, Grassman's law

\begin{abstract}
We advance an explanation for the choice of the invoice currency of international trade contracts on the basis of strategic bargaining considerations. The choice of the invoice currency originates in a situation in which each trader takes into account the other party's bargaining power. The latter depends on the individual discount factor, whether one is the first or second proposer, and whether one is on the short or long side of the market. Along these lines we explain the Grassman bias for trade contracts to be invoiced in the exporter's currency.
\end{abstract}

Apart from the price, the currency of invoice and the forward rate are both major factors influencing the volume of international trade. The forward market as a means of hedging against currency risks has received due attention in the literature (Ethier 1973). However, the choice of the invoice currency has received much less attention. The only empirical law relating to the choice of currencies in foreign trade is Grassman's law, according to which foreign trade is mainly invoiced in the exporter's currency (Grassman 1973; see Bilson 1983 for a macroeconomic explanation). This law has been revisited by several authors (e.g. Black 1985). Deviations from this law are also well recorded (Basevi et al. 1985). In this paper we advance explanations for the choice of the invoice currency on the basis of strategic bargaining considerations. It allows for a wider spectrum of behavior than is indicated by Grassman's law, but at the same time places restrictions on the data which are falsifiable. 
Specifically, we break down the hedge and currency of invoice decision problem into two parts. The first part formulates a simple model of hedging behavior for an exporter and a foreign importer, conditional on the degree of invoicing in the exporter's currency. The main result of this part is to demonstrate how under specific conditions each party has an incentive to invoice in its own currency. The second part of the paper presents two models that describe the invoicing equilibria that can arise under different bargaining processes. If bargaining occurs sequentially, the exporter has more than half of his export revenue invoiced in the domestic currency if he is able to make the first offer. This advantage diminishes the smaller the time interval between offers and the less the discounting of the outcome of the bargaining. If the traders are matched randomly, and who gets to make the first offer is determined randomly as well, the exporters' currency is the dominant currency of invoice if the importers outnumber the exporters, since this conveys some monopoly power to the exporters.

\section{The hedge decision}

This section describes the hedge decision given a particular invoice practice $\lambda$. Consider a domestic exporter and a foreign importer who have agreed to trade one unit of a certain indivisible commodity bundle. ${ }^{1}$ The exporter charges price $p$ for his product in the home currency, whereas he charges $p_{\star}$ in the foreign currency. The domestic currency is assumed to be the exporter's preferred monetary habitat. For this reason his profits are expressed in the domestic currency. The one period ahead profit function $\Pi$ of the exporter reads:

$$
\tilde{\Pi}=\lambda p+(1-\lambda) \tilde{w} p_{\star}-c+(f-\tilde{w}) H,
$$

where $\tilde{w}$ is the random one period ahead domestic price of foreign currency, $f$ is the forward rate, $\mathrm{H}$ is the net supply of forward currency, and $\mathrm{c}$ is the per unit production cost in the domestic currency. Due to trade credit, the exporter is to receive $\lambda p+(1-\lambda) \tilde{w} p_{*}$ one period ahead. Part of the receipts are in the home currency and the other part in the foreign currency, as is indicated by the invoice parameter $\lambda$. To shield himself against the uncertain future spot rate, the merchant can take a hedge $\mathrm{H}$ by buying or selling foreign currency forward.

Assume that the first two conditional moments of $\tilde{w}$ exist such that $\mathrm{E}[\tilde{\mathrm{W}}]=\varepsilon$ and $\operatorname{Var}[\tilde{\mathrm{w}}]=\sigma^{2}$. Assume further that the exporter maximizes 
a mean variance utility function with constant absolute risk aversion parameter $\alpha:^{2}$

$$
\max _{H}: E U=E[\tilde{\Pi}]-\frac{\alpha}{2} \operatorname{Var}[\tilde{\Pi}] .
$$

The optimizing hedge is:

$$
\mathrm{H}=[\uparrow-\varepsilon] / \alpha \sigma^{2}+(1-\lambda) \mathrm{p}_{*} .
$$

The resultant expected utility level reads:

$$
E U=\frac{1}{2}[f-\varepsilon]^{2} / \alpha \sigma^{2}-c+\lambda p+(1-\lambda) f p_{\star} .
$$

Note that the merchant in general only hedges part of his exposure. With a zero risk premium, i.e. $f=\varepsilon$, the exporter hedges completely. Even without any foreign currency risk, i.e. $\lambda=1$, the risk averse merchant still takes a small part of a favorable bet: $H=(f-\varepsilon) / \alpha \sigma^{2}$ (cf. Arrow 1976, p. 100).

Now consider the case that the invoice parameter is not exogenously given but can be determined by the exporter. In order to determine $\lambda$, view the expected utility in equation (4) as a function in $\lambda$. Differentiation gives:

$$
\frac{\partial E U}{\partial \lambda}=p-f p_{*} .
$$

Because $E U$ is linear in $p$, EU increases (decreases) with $\lambda$ as $p>$ $\mathrm{fp}_{*}(<)$. The relevant domain of $\lambda$ is restricted to the interval $[0,1]$, because $\lambda$ refers to the proportion of exports invoiced in the domestic currency. Three solutions may prevail. First, if $p=f p_{*}$, then any $0 \leqslant$ $\lambda \leqslant 1$ generates the same expected utility, and the choice of the invoice currency is not relevant. Second, if $p>f_{*}$, then $\partial E U / \partial \lambda>0$ on $[0,1]$, and expected utility attains its maximum at the corner solution $\lambda=1$. Third, if $p<\mathrm{fp}_{*}$, then $\partial \mathrm{EU} / \partial \lambda<0$ on $[0,1]$, and expected utility attains its maximum at $\lambda=0$. We restrict ourselves to the cases $p<f p_{*}$ or $p>f p_{*}$, when $\lambda=0$ or 1 , and discard the happenstance $\mathrm{p}=\mathrm{fp}_{\mathrm{k}}$. Will $\lambda=0$ or 1 also be the observed outcome?

In order to answer this question, the preferences of the exporter's trade partner come into the picture. Consider a foreign importer who retails the imports abroad against price $s_{\star}$. Assume the importer faces 
the following profit function:

$$
\tilde{\Pi}_{*}=s_{*}-\lambda \frac{p}{\tilde{w}}-(1-\lambda) p_{*}+\left(\frac{1}{\tilde{w}}-\frac{1}{f}\right) H_{*},
$$

where the subscript "*" refers to variables denoted in foreign currency. The foreign currency is assumed to be the preferred monetary habitat of the importer, and hence his profits are expressed in this currency. For simplicity, the profit function (6) is in the same spirit as (1), with the differences stemming from the fact that the importer buys the commodities sold by the domestic exporter. Using (2) again one finds the optimizing choice of $\mathrm{H}_{\star}$ :

$$
\mathrm{H}_{\star}=\left[\varepsilon_{\star}-1 / \mathrm{f}\right] / \alpha \sigma_{\star}^{2}+\lambda \mathrm{p} .
$$

Hence,

$$
E U_{\star}=\frac{1}{2}\left[\varepsilon_{\star}-1 / f\right]^{2} / \alpha \sigma_{\star}^{2}+s_{\star}-(p / f) \lambda-p_{\star}(1-\lambda),
$$

where $\varepsilon_{\star}=\mathrm{E}[1 / \tilde{\mathrm{w}}]$ and $\sigma_{\star}^{2}=\mathrm{E}\left[1 / \tilde{\mathrm{w}}-\varepsilon_{*}\right]^{2}$. Again, viewing $\mathrm{EU} \mathrm{U}_{\star}$ as a function of $\lambda$, differentiating (8) gives:

$$
\frac{\partial E U_{\star}}{\partial \lambda}=-(p / f)+p_{\star} .
$$

Taking the case $p>f p_{*}$, the derivate in (9) is negative and it is optimal for the importer to set $\lambda=0$, i.e., the importer prefers to pay in his own currency. This conflicts with the exporter's preferences and the conflict holds for the other case as well. ${ }^{3}$ Note that the invoice parameter is independent of the hedge decision and both parties' preferences are monotonic in $\lambda$ over the relevant interval. This rules out multiple equilibria and indicates that the relevant variable for the rest of the analysis is $\lambda$ only. Thus the assumption of complete information seems appropriate in this setting. How can we resolve this apparent conflict over $\lambda$ ? The next section attempts to give an answer.

\section{Sequential bargaining over the currency of invoice}

Imagine that both parties bargain over the value of invoice parameter by alternating bids until an agreement is reached. Depending on the 
specifics of the commodity being traded we distinguish between two cases. The first case presumes the bargaining over $\lambda$ can be studied in isolation from market considerations. Such may be the case in the trade of nonstandardized commodities, when there is no outside option. However, for trade in standardized commodities, like the grain trade, market considerations have to be taken into account, because each party can opt out and contact a new partner.

\subsection{No market consideration}

Assume the following bargaining process. Each party, in turn, makes an offer in terms of $\lambda$ and the other party may agree to the offer or reject it. If the other party accepts, the game ends; if the offer is rejected, a counteroffer is made at the next epoch, and so on, with no limit on the number of repetitions of the process. As time is an important factor in international trade, it is assumed that both parties discount the final agreement by a common factor $0 \leqslant \delta \leqslant 1$. The discount factor provides some incentive for the players to reach an agreement. The game is asymmetric because of the need to determine the negotiating order. Rubinstein (1982) showed that a unique solution exists which can be supported as a Perfect Equilibrium. ${ }^{4}$ Table 1 presents the equilibrium solutions $\hat{\lambda}$ conditional upon $p>f p^{*}$ and the exporter having the advantage of making the first offer. In this equilibrium, the exporter receives $\hat{\lambda}=1 /(1+\delta)$ and the importer receives $1-\hat{\lambda}=\delta(1+\delta)$; the exporter is better off because more than half his export revenues are invoiced in the domestic currency $(0<\delta<$ 1). If the importer is the first proposer, the two outcomes have to be interchanged. We have the following result:

Proposition 1. In the bargaining process over the invoice parameter $\lambda$ between an exporter and an importer, the first proposer has an advantage over the second proposer with respect to the determination of the invoice currency. This advantage diminishes the smaller the time interval between offers and the less the discounting of the outcome of the bargaining. For the proof, see Rubinstein (1982) or Sutton (1986).

In view of the above, this suggests that the bias toward the exporter's currency is related to the exporter being the first proposer. The latter conclusion constitutes a falsifiable proposition, but leaves unanswered why the exporter is predominantly the first proposer. Some special cases occur whenever the time between an offer and a counteroffer is 
Table 1. The invoice parameter

\begin{tabular}{lll}
\hline & $\hat{\lambda}$ & $1-\hat{\lambda}$ \\
\hline $0<\delta<1$ & $\frac{1}{1+\delta}$ & $\frac{\delta}{1+\delta}$ \\
$\delta \rightarrow 1$ & $\frac{1}{2}$ & $\frac{1}{2}$ \\
$\delta \rightarrow 0$ & 1 & 0 \\
$t \rightarrow 0$ & $\frac{1}{2}$ & $\frac{1}{2}$ \\
\hline
\end{tabular}

small, or when the two parties do not discount the final outcome. In these cases the equilibrium is at $\hat{\lambda}=\frac{1}{2}$ and the exporter's advantage vanishes. The extreme case $\delta \rightarrow 1$ seems to be appropriate for the trade in capital goods and nonstandardized commodities, as all aspects of the deal need to be investigated and parties exhibit patience. In case parties heavily discount the outcome, $\delta \rightarrow 0$, then the first proposer wins, as the deal would have evaporated by the time the counteroffer is made. The fact that in some commodity markets the invoice currency is determined by custom (mostly trade in primary commodities) reflects the general impatience of agents on these markets. In these latter cases, however, market considerations can be important. For example, the fact that some commodities are well traded vis-à-vis other commodities probably reduces a party's discount factor, as one can easily switch and deal with another merchant.

\subsection{The disequilibrium model}

In this section, market considerations are introduced, the bargainers are matched randomly, and who gets to make the first offer is determined at random as well (Rubinstein and Wolinsky 1985; Rubinstein 1987). The latter can be achieved by introducing a random selection mechanism (such as who places the phone call in case of the grain trade) to determine the first proposer. At each epoch and before the bargaining starts, there is a matching stage in which each agent may meet a new partner. At each matching stage the probability of an exporter meeting an importer is $\alpha$ and the probability of an importer meeting an exporter is $\beta$, with $0<\alpha, \beta \leqslant 1$. If an exporter was in the process of bar- 
gaining in the previous period and did not reach an agreement with an importer, then there are three possible cases in the current period. With probability $\alpha$, the exporter in question abandons his previous partner and meets a new one. With probability $(1-\alpha) \beta$, the exporter is abandoned and does not meet a new partner, but his partner does. With probability $(1-\alpha)(1-\beta)$, both partners continue their bargaining in this period as well. After a trade is concluded both agents leave the market, and are replaced by another importer and exporter. To illustrate the significance of the matching probabilities we shall assume that the number of importers, $\mathrm{m}$, exceeds the number of exporters, $\mathrm{n}$. The probabilities then become $\alpha=1$ and $\beta=n / m$. Hence, at each moment of time, all exporters are involved in trade and some importers cannot be matched to an exporter due to the excess of importers over exporters. The matching probabilities remain constant over time if $n$ and $m$ remain constant as well. The difference between this and the previous setup is that in their bargaining the exporters and importers take the probabilities $\alpha, \beta$ into account, and the risk of losing the deal creates a pressure on the bargaining parties to reach an agreement. We have the following result:

Proposition 2. If market considerations are taken into account, and if the exporter and importer have equal probability to be the first proposer, then members on the short side of the market receive a more favorable invoicing parameter, but their advantage does not enable them to appropriate all the unit surplus. This advantage diminishes the less the discounting of the bargaining, and increases the smaller the time interval between offers. Several cases are reported in Table 2 .

Table 2. The invoice parameter with market considerations

\begin{tabular}{llll}
\hline & $0<\alpha, \beta<1$ & $\alpha=1$ & $\beta=1$ \\
\hline $0<\delta<1$ & $\frac{(1-\delta)+\delta \alpha}{2(1-\delta)+\delta \alpha+\delta \beta}$ & $\frac{1}{2-\delta+\delta \beta}$ & $\frac{(1-\delta)+\delta \alpha}{2-\delta+\delta \alpha}$ \\
$\delta \rightarrow 1$ & $\frac{\alpha}{\alpha+\beta}$ & $\frac{1}{1+\beta}$ & $\frac{\alpha}{1+\alpha}$ \\
$t \rightarrow 0$ & $\frac{1}{2}$ & $\frac{1}{2}$ & $\frac{1}{2}$ \\
\hline & $\frac{\alpha}{\alpha+\beta}$ & $\frac{1}{1+\beta}$ & $\frac{\alpha}{1+\alpha}$ \\
\hline
\end{tabular}


Proof. (Rubinstein 1987) Denote by $\hat{\lambda}$ the equilibrium invoice parameter. Let $V(t)$ and $V_{*}(t)$ be the expected values for an exporter and an importer, respectively, of being in the market before it is known whether they are matched. These values are a weighted average of the value of being able to bargain now and not being able to bargain during the current period:

$$
\begin{aligned}
& \mathrm{V}(\mathrm{t})=\alpha \hat{\lambda}(\mathrm{t})+(1-\alpha) \delta \mathrm{V}(\mathrm{t}+1), \\
& \mathrm{V}_{*}(\mathrm{t})=\beta[1-\hat{\lambda}(\mathrm{t})]+(1-\beta) \delta \mathrm{V}_{*}(\mathrm{t}+1)
\end{aligned}
$$

In equilibrium, the invoice parameter offered at $t+1$ by an importer to his export partner is valued at time $t$ as $\delta V(t+1)$. Similarly, the invoice parameter offered by an exporter to the importer is valued as [1 $\left.\delta \mathrm{V}_{\star}(\mathrm{t}+1)\right]$. Since the toss of a coin determines the first proposer, we have:

$$
\hat{\lambda}(\mathrm{t})=\left[1-\delta \mathrm{V}_{*}(\mathrm{t}+1)\right] / 2+\delta \mathrm{V}(\mathrm{t}+1) / 2 .
$$

The solution $\hat{\lambda}(\mathrm{t})$ to the above three equations then takes the form:

$$
\lambda(t)=\frac{(1-\delta)+\delta \alpha}{2(1-\delta)+\delta \alpha+\delta \beta} .
$$

The proposition is of interest because it relates the value of $\lambda$ to the relative number of exporters to importers, $\beta=\mathrm{n} / \mathrm{m}$. This number is in principle an observable quantity. There are some reasons, a priori, to believe that $n<m$. To take the case of the Netherlands, for example, there are 7,701 registered exporters and 9,406 importers. Out of the total of these two numbers, $21 \%$ of the firms are producing manufacturers, with 2,923 engaged in exporting and 723 importing. A much larger group comprising $54 \%$ of the total do not produce but are just engaged in trade. Of this latter group, 2,824 focus exclusively on exports, while 6,325 only deal in imports. ${ }^{5}$ Given that production of manufacturers is concentrated in firms, while consumption is spread over a much larger number of households, one expects that there are many more distributors and hence importers than producing firms and exporters. This gives the exporter a bargaining advantage over the importer, as the exporter has a better chance of finding another partner in case the deal is off. Thus our analysis shows that Grassman's law is possibly a manifestation of the asymmetry in bargaining power between importers and exporters. To broaden the scope of this conclusion, a 
case in which both the currency of invoice and the price are negotiable is of potential interest for future research. ${ }^{6}$

\section{Acknowledgements}

The paper benefitted from the seminar discussions at the University of Amsterdam and the Bologna Summer Meeting of the Econometric Society. We are grateful to D. Kovenock, M. Schafgans, A. de Vaal and the referees for helpful comments and suggestions on earlier versions of the paper.

\section{Notes}

1. This analysis can be extended to incorporate the quantity decision as well, but is omitted for considerations of space; cf. Ethier (1973).

2. For the results (see equations (5) and (10)), it is immaterial whether agents have different attitudes toward risk, provided they are all risk averse, or have diverse precisions; cf. Stein (1985). To streamline the presentation we assume identical behavior.

3. In the case that there are no forward markets, i.e., $H=H_{\star}=0$, it is immediate that the merchants unambiguously prefer to invoice in their own currency.

4. An intuitive proof and discussion is provided in Sutton (1986).

5. Data Source: NV Databank Adressen Catalogus, NV Databank, Woerden, 1987.

6. The collinearity between the two instruments necessitates analysis which is outside the scope of this paper.

\section{References}

Arrow, K. J. (1976) Essays in the Theory of Risk-Bearing (Amsterdam: North-Holland).

Basevi, G., D. Cocchi, and P. L. Lischi (1985) "The Choice of Currency in the Foreign Trade of Italy," Research Paper No. 17, University of Bologna.

Bilson, J. F. O. (1983) "The Choice of an Invoice Currency in International Transactions." In J. S. Bhandari and B. H. Putnam (eds), Economic Interdependence and Flexible Exchange Rates (Cambridge: MIT Press), pp. 384-402.

Black, S. W. (1985) "International Money and International Monetary Arrangements." In R. W. Jones and P. B. Kenen (eds), Handbook of International Economics (Amsterdam: North-Holland), pp. 1153-1194.

Ethier, W. J. (1973) "International Trade and the Forward Exchange Market," American Economic Review 63, 494-503.

Grassman, S. (1973) "A Fundamental Symmetry in International Payment Patterns," Journal of International Economics 3, 105-116.

Rubinstein, A. (1982) "Perfect Equilibrium in a Bargaining Model," Econometrica 50, 97-110 
Rubinstein, A. (1987) "Perfect Equilibrium in a Market with Decentralized Trade and Strategic Behaviour: An Introduction," Theoretical Economics Discussion Paper Series $87 / 147$, London School of Economics.

Rubinstein, A. and A. Wolinksy (1985) "Equilibrium in a Market with Sequential Bargaining," Econometrica 53, 1133-1150.

Stein, J. L. (1985) "Exchange Rate Management with Rational Expectations but Diverse Precisions." In J. S. Bhandari (ed.), Exchange Rate Management under Uncertainty (Cambridge: MIT Press), pp. 96-125.

Sutton, J. (1986) "Non-Cooperative Bargaining Theory: An Introduction," Review of Economic Studies 53, 709-724. 